Rev. Int. Contam. Ambie. 36 (3) 577-591, 2020

https://doi.org/10.20937/RICA.53425

\title{
LA APLICACIÓN DE LODOS RESIDUALES AFECTA, A CORTO PLAZO, LA BIOMASA MICROBIANA Y SU ACTIVIDAD EN SUELOS SÓDICOS
}

The application of sewage sludge affects, in the short term, microbial biomass and its activity in sodic soils

\author{
Miriam del Rocío MEDINA-HERRERA ${ }^{1}$, María de la Luz Xochilt NEGRETE-RODRÍGUEZ ${ }^{1}$, \\ Francisco Paul GÁMEZ-VÁZQUEZ ${ }^{2}$, Dioselina ÁLVAREZ-BERNAL ${ }^{3}$ y Eloy CONDE-BARAJAS ${ }^{1}$ *
}

${ }^{1}$ Departamento de Ingeniería Ambiental y Posgrado de Ingeniería Bioquímica, Tecnológico Nacional de México/ IT de Celaya, Antonio García Cubas 600, Col. Fovissste, 38010 Celaya, Guanajuato, México

${ }^{2}$ Instituto Nacional de Investigaciones Forestales, Agrícolas y Pecuarias (INIFAP), Campo Experimental Bajío, km. 6.5 carretera Celaya-San Miguel de Allende, 38010 Celaya, Guanajuato, México

${ }^{3}$ Centro Interdisciplinario de Investigación para el Desarrollo Integral Regional, Instituto Politécnico Nacional, Unidad Michoacán, Justo Sierra 28, Centro, 59510 Jiquilpan, Michoacán, México

*Autor para correspondencia: eloy.conde@itcelaya.edu.mx

(Recibido: noviembre 2018; aceptado: noviembre 2019)

Palabras clave: hidrólisis FDA, mineralización C y N, enmienda orgánica, sodicidad

\section{RESUMEN}

El efecto de la aplicación de lodos residuales a un suelo sódico sobre la mineralización de $\mathrm{C}$ y N, biomasa microbiana, actividad enzimática microbiana e indicadores biológicos fueron evaluados. El suelo sódico fue agrícola y el experimento de incubación se realizó a nivel laboratorio a 56 días con tres tratamientos: suelo sódico testigo (T1), suelo sódico más lodos en $20 \mathrm{Mg} / \mathrm{ha}$ (T2) y en $40 \mathrm{Mg} / \mathrm{ha}$ (T3). Los resultados obtenidos para T2 y T3 fueron: C mineralizado, 56.89 y $33.81 \%$; N mineralizado, 3.04 y $1.66 \%$, y C incorporado a la biomasa microbiana en relación con el testigo (T1), 0.81 y $0.50 \%$. La actividad enzimática microbiana se incrementó 2.81 y 3.59 veces para T2 y T3 con respecto a T1. Los indicadores biológicos $\mathrm{qCO}_{2}$, qFDA y $\mathrm{N}_{\min } / \mathrm{C}_{\text {mic }}$ se incrementaron al inicio de la dinámica de mineralización y disminuyeron paulatinamente. La aplicación de lodos residuales al suelo sódico tuvo un efecto positivo sobre la mineralización de $\mathrm{C}$ y N , así como en la biomasa microbiana a corto plazo. El tratamiento T2 presentó una mayor eficiencia en la mineralización e incorporación de $\mathrm{C}$, pero respecto a la mineralización de $\mathrm{N}$ y actividad enzimática microbiana no se encontraron diferencias significativas entre los tratamientos T2 y T3. Se recomienda evaluar las dosis de aplicación de los lodos residuales antes de su aplicación a suelos sódicos. Es la primera vez que se reporta el uso de indicadores biológicos para evaluar la aplicación de lodos residuales en un suelo sódico mexicano.

Key words: FDA hydrolysis, $\mathrm{C}$ and $\mathrm{N}$ mineralization, organic amendment, sodicity

\begin{abstract}
The effect of applying sewage sludge to sodic soil on $\mathrm{C}$ and $\mathrm{N}$ mineralization, microbial biomass, microbial enzymatic activity and biological indicators were evaluated. The sodic soil was agricultural, and the incubation experiment was performed at the
\end{abstract}


laboratory level at 56 days with three treatments: control sodic soil group (T1), sodic soil + sewage sludge at $20 \mathrm{Mg} / \mathrm{ha}$ (T2) and at $40 \mathrm{Mg} / \mathrm{ha}$ (T3). The results obtained for T2 and T3 were: 56.89 and $33.81 \%$ mineralized C, 3.04 and $1.66 \%$ mineralized $\mathrm{N}$, 0.81 and $0.50 \%$ immobilized carbon by microbial biomass in relation to control (T1). The microbial enzymatic activity increased 2.81 and 3.59 times for T2 and T3 with respect to T1. In the biological indicators $\mathrm{qCO}_{2}, \mathrm{qFDA}$ and $\mathrm{N}_{\mathrm{min}} / \mathrm{C}_{\mathrm{mic}}$, an increase was observed at the beginning of the mineralization dynamics and gradually decreased over time. The application of sewage sludge to sodic soil had a positive effect on the mineralization of $\mathrm{C}$ and $\mathrm{N}$, as well as microbial biomass in the short term. The T2 treatment presented a greater efficiency in the mineralization and immobilization of $\mathrm{C}$, but with respect to $\mathrm{N}$ mineralization and microbial enzymatic activity no significant differences were found between T2 and T3. It is recommended to evaluate the application doses of the sewage sludge before its application to sodic soils. It is the first time that the use of biological indicators has been reported to evaluate the application of sewage sludge in a sodic soil of Mexico.

\section{INTRODUCCIÓN}

Los lodos residuales son agregados constituidos por microorganismos, nutrientes y sustancias poliméricas extracelulares producto del tratamiento de las aguas residuales (Edwards et al. 2017, Zhang et al. 2017). La aplicación de lodos residuales al suelo es la práctica preferida para el manejo de estos residuos a nivel internacional, ya que ofrece la posibilidad de reciclar la materia orgánica y nutrientes, evitando impactos ambientales y económicos asociados con otras opciones de eliminación como vertederos o incineración (Rigby et al. 2016, Praspaliauskas y Pedisius 2017, Torri et al. 2017). Además, la incorporación de lodos residuales puede contribuir al secuestro de $\mathrm{C}$ en el suelo y reducir la emisión de gases de efecto invernadero (Tian et al. 2009, Torri et al. 2017). Sin embargo, dichos lodos pueden contener moléculas poliméricas no fácilmente asimilables y elementos tóxicos como metales pesados, microorganismos patógenos y parásitos (Rigby et al. 2016, Zhang et al. 2017). Asimismo, la aplicación de lodos residuales con elevada carga de nutrientes al suelo puede ocasionar lixiviados al subsuelo y contaminar aguas subterráneas (Torri et al. 2017, Zhang et al. 2017); por lo tanto, deben ser estabilizados y caracterizados, y sus dosis de aplicación deben ser evaluadas, a nivel microcosmos, antes de su aplicación a nivel campo. En México, la utilización de lodos residuales está regulada por la Norma Oficial Mexicana NOM-004-SEMARNAT-2002 (SEMARNAT 2003), que establece las especificaciones y límites máximos permisibles de contaminantes para su aprovechamiento y disposición final. Al cumplir con la normatividad, los lodos residuales pueden ser aprovechados como abonos orgánicos de disposición final en suelos agrícolas, forestales y pastizales (Jurado-Guerra et al. 2004, Potisek-Talavera et al. 2010). En Estados
Unidos y la Unión Europea, aproximadamente el 49 $\%$ y $36 \%$, de los lodos residuales son aprovechados en la agricultura, respectivamente (Iranpour et al. 2004, Rigby et al. 2016), mientras que en México se desconoce la proporción exacta de aplicación de lodos residuales a suelos agrícolas. No obstante, en el estado de Guanajuato ya se están aplicando lodos residuales como enmienda orgánica a suelos agrícolas sin previo estudio a nivel microcosmos que permita conocer la dosis correcta de aplicación y sus efectos a corto plazo en la calidad del suelo (Jurado et al. 2007, Zanor et al. 2018).

Por otro lado, los suelos afectados por sales de sodio se encuentran comúnmente en regiones áridas y semiáridas, y se extienden gradualmente a varias regiones del mundo (Jurado-Guerra et al. 2004, Ferreira et al. 2016). Se estima que aproximadamente 950 millones de hectáreas de suelo están afectadas por problemas de salinidad-sodicidad, lo cual afecta la calidad de casi $33 \%$ de los suelos agrícolas (Wong et al. 2010, Rigby et al. 2016).

Las propiedades físicas del suelo son afectadas por la sodicidad debido a un incremento de la hinchazón y dispersión de las arcillas, lo cual solubiliza la materia orgánica; en consecuencia origina pérdida de porosidad, permeabilidad, infiltración, conductividad hidráulica y, por lo tanto, afecta la estructura del suelo (Wong et al. 2009, 2010, Srivastava et al. 2016). Estas variables, en conjunto, pueden afectar la mineralización de la materia orgánica y la magnitud de las emisiones de $\mathrm{C}-\mathrm{CO}_{2}$ del suelo, debido a un incremento inadecuado de la actividad microbiana (Wong et al. 2010, Mavi et al. 2012).

Sin embargo, lo anterior puede variar en función de la calidad y cantidad de la materia orgánica fresca que entra en el suelo (Wang et al. 2015), por lo que una alternativa viable para el manejo de suelos sódi- 
cos podría ser el uso de lodos residuales (SánchezMonedero et al. 2004, Giacomini et al. 2015, Singh 2016) que permita la unión de las partículas pequeñas en agregados estables e incremente su porosidad, mejorando de esta manera algunas propiedades físicas del suelo (Wong et al. 2010, Srivastava et al. 2016). Asimismo, la aplicación de lodos residuales en suelos sódicos enriquece la rizosfera con micro y macronutrientes (Larney y Angers 2012). Esto produce efectos positivos importantes en la fertilidad, las tasas de nitrificación, el tamaño de la población de microorganismos y las actividades enzimáticas como proteasas, esterasas y lipasas de los suelos agrícolas (Kelly et al. 2011, Błońska et al. 2017).

La mineralización de la materia orgánica del suelo es controlada por el tamaño y la actividad de la biomasa microbiana, la cual puede responder a las perturbaciones en una escala de tiempo menor a las propiedades fisicoquímicas. De esta manera, algunos parámetros biológicos y microbiológicos del suelo como el carbono de biomasa microbiana (C-BM), la tasa de respiración microbiana, el cociente metabólico microbiano $\left(\mathrm{qCO}_{2}\right)$, la actividad hidrolítica específica (qFDA) y las actividades enzimáticas se han utilizado como indicadores de los cambios provocados por perturbaciones al suelo y para monitorear los efectos a corto y largo plazo de la aplicación de lodos residuales u otras enmiendas orgánicas sobre la calidad del suelo (Perucci et al. 2000, Melero et al. 2009, Sofo et al. 2012, Ferreras et al. 2015, Roohi et al. 2016, Błońska et al. 2017, Gajda et al. 2018).

Sin embargo, a pesar de los extensos estudios sobre los efectos de la aplicación de lodos residuales sobre dinámicas de mineralización-asimilación de $\mathrm{C}$ y $\mathrm{N}$, propiedades fisicoquímicas y biomasa microbiana en los suelos (Boeira et al. 2002, Beltrán-Hernández et al. 2007, Franco-Otero et al. 2012, Sciubba et al. 2014, Araújo et al. 2015, 2016, Giacomini et al. 2015, Bhaduri et al. 2016, de Sousa et al. 2017, Trivedi et al. 2017), se tiene poco conocimiento de los efectos de la aplicación a corto plazo de lodos residuales sobre la actividad microbiana e indicadores biológicos de la calidad del suelo en suelos sódicos. Por ello, comprender estos efectos es de suma importancia para establecer planes adecuados de dosificación y la posterior aplicación de lodos residuales a suelos sódicos agrícolas en México.

Con este fin se diseñó un estudio a nivel microcosmos, utilizando lodos residuales a dos dosis de aplicación (20 y $40 \mathrm{Mg} / \mathrm{ha}$ ) que actualmente se aplican a nivel campo en suelos agrícolas en la región Bajío del estado de Guanajuato. Así, el objetivo fue evaluar cómo la aplicación de lodos residuales a diferentes dosis afecta a corto plazo la mineralización de $\mathrm{C}$ y $\mathrm{N}$, el C-BM, la actividad microbiana expresada en la emisión de $\mathrm{C}-\mathrm{CO}_{2}$ y qCO 2 , y la qFDA en el suelo.

\section{MATERIALES Y MÉTODOS}

El estudio se realizó en suelo sódico agrícola ubicado cerca del municipio de Cortázar, Guanajuato ( $\left.20^{\circ} 26.419^{\prime} \mathrm{N}, 100^{\circ} 58.898^{\circ} \mathrm{O}\right)$, donde se seleccionó un área representativa de $100 \times 100 \mathrm{~m}$ para el muestreo. El área se dividió en tres secciones iguales y el método utilizado fue el de "zigzag" (SEMARNAT 2002). La muestra de suelo se tomó a una profundidad de 20-25 cm correspondiente a la zona arable de los suelos agrícolas. En cada sección se recolectó una muestra compuesta de $6.5 \mathrm{~kg}$, aproximadamente. Las muestras de suelo se trasladaron al laboratorio, se secaron al aire, se homogenizaron y se tamizaron en una malla con apertura de trama de $2 \mathrm{~mm}$ para ser almacenadas a $4{ }^{\circ} \mathrm{C}$ hasta su análisis.

Los lodos se obtuvieron de un tratamiento biológico secundario de aguas residuales urbanas y deshidratados al sol en una planta tratadora de aguas residuales (PTAR) de la región Bajío. Los lodos residuales fueron categorizados como clase "C", aptos para su uso como mejoradores de suelos agrícolas según lo establecido en la normatividad mexicana (SEMARNAT 2002).

Tanto el suelo como los lodos residuales se caracterizaron física y químicamente antes del experimento a nivel microcosmos. El pH se determinó por método potenciométrico en una solución suelo-agua $(1: 5 \mathrm{~m} / \mathrm{v})$ según lo establecido por Thomas (1996). La conductividad eléctrica (CE) se midió en una solución suelo-agua desionizada $(1: 2.5 \mathrm{~m} / \mathrm{v})$ con un conductímetro digital por el método de Rhoades (1996). La densidad aparente $\left(\rho_{\mathrm{a}}\right)$ se determinó introduciendo cuidadosamente un cilindro metálico en el suelo durante el muestreo en campo. Posteriormente el suelo obtenido llevó al laboratorio, se secó en estufa a 105 ${ }^{\circ} \mathrm{C}$, se pesó y se calculó la densidad aparente mediante la relación de la masa de suelo seco y el volumen del cilindro (Blake y Hartge 1986). La textura del suelo se determinó por el método de Bouyoucos (Gee y Bauder 1986), y el carbono orgánico total (COT) por oxidación con dicromato de potasio según el método de Nelson y Sommers (1996). El nitrógeno total (NT) se analizó por sistema micro-Kjeldhal (Bremner 1996). La relación C/N se calculó con los valores obtenidos de COT y NT. Los cationes intercambiables $\left(\mathrm{Na}^{+}, \mathrm{K}^{+}, \mathrm{Ca}^{+2}\right.$ y $\left.\mathrm{Mg}^{+2}\right)$ y la capacidad de intercambio catiónico (CIC) se determinaron por el método espectrofotométrico de absorción atómica 
con acetato de amonio $1 \mathrm{M}$ (Rhoades 1982, Thomas 1982). El porcentaje de sodio intercambiable (PSI) fue determinado mediante la relación de los cationes intercambiables como establece Sumner (1993) en la ecuación 1.

$$
\begin{aligned}
& \text { PSI }=\frac{\mathrm{Na}^{+}}{\mathrm{CIC}} \times 100= \\
& \quad \frac{\mathrm{Na}^{+}}{\sum\left(\mathrm{Ca}^{+2}+\mathrm{Mg}^{+2}+\mathrm{Na}^{+}+\mathrm{K}^{+}\right)} \times 100
\end{aligned}
$$

Para evaluar el efecto de la aplicación de lodos residuales sobre la actividad microbiana en el suelo, se establecieron experimentos a nivel microcosmos por cada sección muestreada y por triplicado. Se diseñó un experimento con tres tratamientos: $\mathrm{T} 1$ : suelo sin lodo, como testigo; T2: suelo más lodo en dosis de $20 \mathrm{Mg}$ / ha, y T3: suelo más lodo en dosis de $40 \mathrm{Mg} / \mathrm{ha}$. Cada microcosmos consistió en un frasco de vidrio de $1 \mathrm{~L}$ que contenía un frasco de $90 \mathrm{~mL}$, aproximadamente, con $20 \mathrm{~g}$ de suelo al $50 \%$ de su capacidad de retención de agua (CRA) más el lodo residual. Además, en el interior del frasco se colocó un vial con $20 \mathrm{~mL}$ de una solución de $\mathrm{NaOH} 0.5 \mathrm{M}$ para capturar el C- $\mathrm{CO}_{2}$ emitido. Los frascos se cerraron herméticamente y se incubaron a $25{ }^{\circ} \mathrm{C}$ en la oscuridad. En el día de muestreo tres microcosmos de cada tratamiento y de cada sección muestreada fueron seleccionados aleatoriamente para sus análisis (Pampillón-González et al. 2017). La dinámica de los diferentes parámetros medidos a través del tiempo se realizó a los 3, 7, 14, 28 y 56 días. Los parámetros analizados fueron $\mathrm{C}$ mineralizado a partir del $\mathrm{CO}_{2}$ emitido $\left(\mathrm{C}-\mathrm{CO}_{2}\right), \mathrm{N}$ neto mineralizado $\left(\mathrm{N}_{\text {min }}\right)$, la actividad enzimática microbiana mediante hidrólisis de diacetato de fluoresceína (AEM-FDA) y el carbono de la biomasa microbiana (C-MB). La emisión de $\mathrm{C}-\mathrm{CO}_{2}$ se determinó por valoración volumétrica de $5 \mathrm{~mL}$ de $\mathrm{NaOH} 0.5 \mathrm{M}$ con $\mathrm{HCl} 0.5 \mathrm{M}$ y fenolftaleína como indicador (Beltrán-Hernández et al. 2007). El C-CO $\mathrm{CO}_{2}$ emitido por la mineralización de lodos residuales se determinó como la diferencia entre la emisión de $\mathrm{C}-\mathrm{CO}_{2}$ en los tratamientos con lodos residuales (T2, y T3) y el C- $\mathrm{CO}_{2}$ emitido en el testigo (T1), determinándose también los porcentajes de mineralización del C orgánico adicionado (RojasOropeza et al. 2010). El contenido de nitrógeno inorgánico $\left(\mathrm{N}-\mathrm{NH}_{4}{ }^{+}, \mathrm{N}_{-} \mathrm{NO}_{3}{ }^{-}\right.$y N-NO$\left.{ }_{2}{ }^{-}\right)$se extrajo con una solución de $\mathrm{K}_{2} \mathrm{SO}_{4} 0.5 \mathrm{M}$ en una relación $1: 4(\mathrm{~m} / \mathrm{v})$ y cada forma de nitrógeno inorgánico se fue cuantificó por el método colorimétrico (Conde et al. 2005). El $\mathrm{N}_{\text {min }}$ a través del tiempo se determinó mediante la sumatoria de las formas inorgánicas de nitrógeno (Rustad et al. 2001). El porcentaje de $\mathrm{N}_{\min }$ proveniente de los biosólidos fue determinado según lo establecido por Wang et al. (2003). El C-BM se determinó por el método de respiración inducida por sustrato (SIR, por sus siglas en inglés), utilizando glucosa como sustrato a una concentración de $16 \mathrm{~g} / \mathrm{kg}$, y el valor obtenido se expresó como $\mathrm{mg} \mathrm{C}_{\mathrm{mic}} / \mathrm{kg}$ suelo seco (Anderson y Domsch 1978). En los tratamientos y a través del tiempo, la AEM-FDA, que contempla las familias de esterasas, proteasas y lipasas (Sciubba et al. 2014, Wang et al. 2017), se determinó mediante hidrólisis del diacetato de fluoresceína (FDA, por sus siglas en inglés), método colorimétrico establecido por Adam y Duncan (2001).

La dinámica a través del tiempo del $\mathrm{qCO}_{2}$ se calculó como el cociente del valor del C- $\mathrm{CO}_{2}$ emitido por respiración microbiana y el C-BM (Anderson y Domsch 1990), expresándose como mg C-CO $\mathrm{CO}_{2} / \mathrm{mg}$ $\mathrm{C}_{\text {mic }} / \mathrm{h}$. Similarmente, la actividad hidrolítica específica (qFDA) fue determinada como el cociente del FDA hidrolizado y el C-BM, expresándose como mg FDA hidrolizado/mg $\mathrm{C}_{\text {mic }} / \mathrm{h}$ (Perucci et al. 2000).

La relación entre el $\mathrm{N}_{\min } \mathrm{y}$ el C-BM $\left(\mathrm{N}_{\min } / \mathrm{C}_{\mathrm{mic}}\right)$ se determinó para evaluar una relación entre mineralización de nitrógeno con la biomasa microbiana al adicionar el lodo residual al suelo. La relación $\mathrm{N}_{\text {min }} / \mathrm{C}_{\text {mic }}$ se obtuvo mediante el cociente del $\mathrm{N}_{\text {min }}$ entre el contenido de C-BM y se expresó como mg $\mathrm{N}_{\text {min }} / \mathrm{mg} \mathrm{C}_{\text {mic }}$.

El diseño del experimento fue completamente al azar y se utilizó la media para las diferentes variables evaluadas en cada tiempo de muestreo. Además, se obtuvo la media acumulada para cada tratamiento. Los datos obtenidos en ambos casos fueron sometidos a pruebas de homogeneidad de varianzas y normalidad de acuerdo con Celis et al. (2013); posteriormente se procesaron mediante ANOVA de un factor. La comparación de medias se realizó mediante la prueba de Tukey. Las diferencias estadísticamente significativas para todas las variables fueron establecidas a un nivel del $95 \%(\mathrm{p} \leq 0.05)$. Los resultados obtenidos se analizaron empleando el software Minitab 18 (Franco-Otero et al. 2012, Ferreras et al. 2015, Minitab 2018).

\section{RESULTADOS Y DISCUSIÓN}

Los resultados de la caracterización física y química del suelo y el lodo residual se muestran en el cuadro I. El suelo presentó un $\mathrm{pH}$ de 8.57 , el cual lo clasifica como fuertemente alcalino. La C. fue menor a $1 \mathrm{dS} / \mathrm{m}$, por lo cual no presentó problemas de salinidad. La densidad aparente fue de $1.10 \mathrm{~g} / \mathrm{mL}$ (SEMARNAT 2002). La composición granulomé- 
CUADRO I. CARACTERÍSTICAS FÍSICAS Y QUÍMICAS DEL SUELO AGRÍCOLA Y LODOS DEL TRATAMIENTO DE AGUAS RESIDUALES

\begin{tabular}{lccc}
\hline Variable & Unidades & Suelo & Lodos \\
\hline $\mathrm{pH}$ & - & 8.57 & 6.62 \\
$\mathrm{CE}$ & $\mathrm{dS} / \mathrm{m}$ & 0.54 & 1.15 \\
$\rho_{\mathrm{a}}$ & $\mathrm{g} / \mathrm{mL}$ & 1.10 & 0.78 \\
$\mathrm{Textura}$ & - & Arcilloso & $\mathrm{NA}$ \\
$\mathrm{COT}$ & $\mathrm{g} / \mathrm{kg}$ & 7.6 & 523.6 \\
$\mathrm{NT}$ & $\mathrm{g} / \mathrm{kg}$ & 3.94 & 86.2 \\
$\mathrm{C} / \mathrm{N}$ & - & 1.93 & 6.07 \\
$\mathrm{Na}^{+}$ & $\mathrm{mg} / \mathrm{kg}$ & 1026 & 10700 \\
$\mathrm{~K}^{+}$ & $\mathrm{mg} / \mathrm{kg}$ & 574 & 1700 \\
$\mathrm{Ca}^{+2}$ & $\mathrm{mg} / \mathrm{kg}$ & 2554 & 20300 \\
$\mathrm{Mg}^{+2}$ & $\mathrm{mg} / \mathrm{kg}$ & 422 & 7400 \\
$\mathrm{CIC}$ & $\mathrm{meq} / 100 \mathrm{~g}$ & 22.2 & 194.66 \\
$\mathrm{PSI}$ & $\%$ & 20.08 & $\mathrm{NA}$ \\
\hline
\end{tabular}

Nota: Los gramos o kilogramos corresponden a la base seca de suelo o lodo residual, según sea el caso

NA: no aplica, CE: conductividad eléctrica, $\rho_{a}$ densidad aparente, COT: carbón orgánico total, NT: nitrógeno total, $\mathrm{C} / \mathrm{N}$ : relación carbono/nitrógeno, CIC: capacidad de intercambio catiónico, PSI: porcentaje de sodio intercambiable

trica consistió en $13.12 \%$ arena, $52.16 \%$ arcilla y $34.72 \%$ limo; de esta manera, la textura del suelo fue arcilloso según Shirazi y Boersma (1984). El contenido de COT y NT se clasificó como muy bajo conforme a la normatividad mexicana (SEMARNAT 2002). La relación $\mathrm{C} / \mathrm{N}$ fue muy baja, lo cual indica que se trata de un suelo con falta de energía y con tendencia a la alta liberación de $\mathrm{N}$ mineral (Studdert et al. 2017). El valor de CIC obtenido corresponde a un suelo de fertilidad media (SEMARNAT 2002). Por último, el suelo se clasificó como sódico por presentar un valor de PSI > $15 \%$ y un $\mathrm{pH}>8.5$ (Sumner 1993).

En el cuadro I también se muestran los resultados obtenidos para las características físicas y químicas de los lodos residuales. El $\mathrm{pH}$ del lodo fue moderadamente ácido, con un valor de 6.62. La CE tuvo un valor de $1.15 \mathrm{dS} / \mathrm{m}$. La densidad aparente fue baja, lo cual se atribuyó a su naturaleza arenosa proveniente del tratamiento de aguas residuales y el método de estabilización empleado. El contenido de COT (526 $\mathrm{mg} / \mathrm{kg})$ fue medio y el de NT $(86.2 \mathrm{mg} / \mathrm{kg})$ fue alto (Pérez et al. 2008). La relación $\mathrm{C} / \mathrm{N}$ fue de 6.07, por lo cual los lodos residuales se clasifican como abono estabilizado respecto al contenido de nutrientes (Pérez et al. 2008). El valor obtenido para CIC (194.66 meq/100 g) fue muy elevado (Liew et al. 2004).

Para los diferentes tratamientos y a través del tiempo, la mineralización de $\mathrm{C}$ orgánico se observó mediante la emisión de $\mathrm{C}-\mathrm{CO}_{2}$ (Figs. 1 y 2). En los tratamientos con aplicación de lodos residuales (T2 y T3) se encontró un incremento significativo $(\mathrm{F}=9.98$, $\mathrm{p}=0.01)$ en la dinámica de emisión $\mathrm{C}-\mathrm{CO}_{2}$ con relación al testigo (Fig. 1). Los valores de emisiones de $\mathrm{C}-\mathrm{CO}_{2}$ del tratamiento T2 para el día $3(840 \mathrm{mg} / \mathrm{kg})$ presentaron un incremento de $4426.67 \mathrm{mg} / \mathrm{kg}$ a los 56 días de experimentación. Asimismo, el valor de emisión de $\mathrm{C}-\mathrm{CO}_{2}$ para el tratamiento $\mathrm{T} 3$ tuvo un incremento de $4596.67 \mathrm{mg} / \mathrm{kg}$ para el día 56 con relación al valor registrado el día $3(1613.33 \mathrm{mg} / \mathrm{kg})$, mientras que los valores de emisión de $\mathrm{C}-\mathrm{CO}_{2}$ del tratamiento T1 solamente se incrementaron $120 \mathrm{mg} / \mathrm{kg}$ en el mismo periodo.

$\mathrm{El}$ incremento en los valores de emisión de $\mathrm{C}-\mathrm{CO}_{2}$

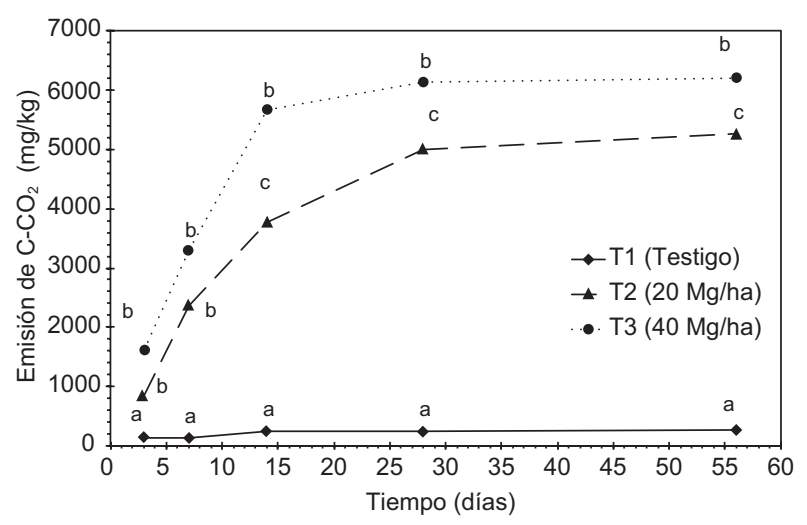

Fig. 1. Dinámica de la emisión de C-CO $(\mathrm{mg} \mathrm{C} / \mathrm{kg}$ suelo seco) durante 56 días de incubación. Las letras diferentes en los puntos de la dinámica indican diferencias significativas entre tratamientos $(\mathrm{p} \leq 0.05)$

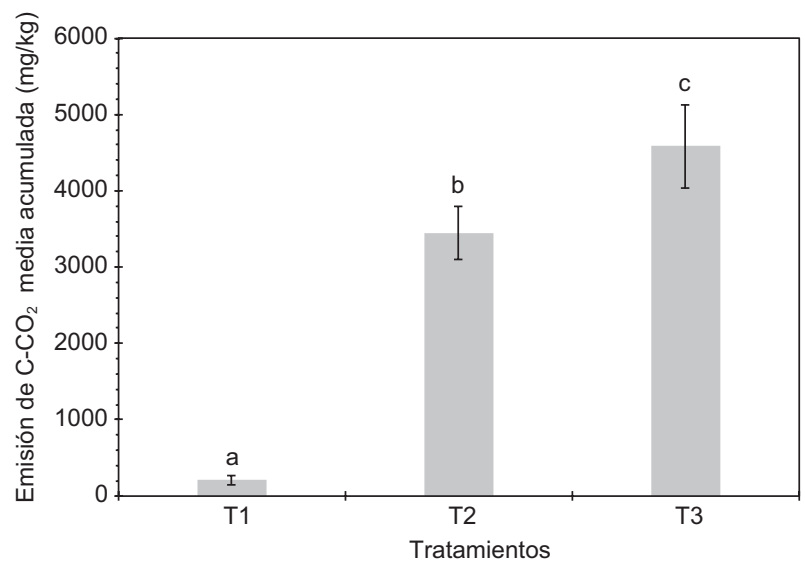

Fig. 2. Media acumulada de la emisión de $\mathrm{C}-\mathrm{CO}_{2}(\mathrm{mg} \mathrm{C} / \mathrm{kg}$ suelo seco) durante los 56 días de incubación. Tratamientos: T1 (testigo), T2 (20 Mg/ha) y T3 (40 Mg/ha). Las líneas en las barras representan la desviación estándar para cada tratamiento y letras diferentes indican diferencias significativas entre tratamientos $(\mathrm{p} \leq 0.05)$ 
debido a la descomposición del C orgánico presente después de la aplicación de los lodos residuales se atribuyó a una estimulación de la actividad microbiana en respuesta a cantidades modificadas de diferentes fuentes de $\mathrm{C}$ y $\mathrm{N}$ fácilmente asimilables, como ha sido reportado en otros estudios (Perelo y Munch 2005, Larney y Angers 2012, Thangarajan et al. 2013, Pires et al. 2017). En los tratamientos T2 y $\mathrm{T} 3$, la emisión de $\mathrm{C}-\mathrm{CO}_{2}$ por la mineralización de los lodos residuales en el día 56 fue de 5006.67 y 5950.00 $\mathrm{mg} / \mathrm{kg}$, respectivamente. Sin embargo, al final del tiempo de incubación el C orgánico aportado por los lodos residuales se mineralizó en un 56.89 y $33.81 \%$ para T2 y T3, respectivamente. Estos porcentajes de mineralización fueron significativamente diferentes $(\mathrm{F}=24.13, \mathrm{p}=0.007)$. De lo anterior, se estableció que T2 presentó una mayor mineralización de $\mathrm{C}$ orgánico proveniente de los lodos residuales en el suelo sódico durante el periodo de experimentación, incluso cuando sus valores de emisión de $\mathrm{C}-\mathrm{CO}_{2}$ respecto a $\mathrm{T} 3$ fueron menores.

Paustian et al. (2000) establecieron que los niveles de $\mathrm{C}$ orgánico en un suelo agrícola se rigen por el equilibrio entre las entradas de $\mathrm{C}$ (residuos de cultivos o enmiendas orgánicas) y las pérdidas de $\mathrm{C}$ (emisión de $\mathrm{C}-\mathrm{CO}_{2}$ ), principalmente a través de la mineralización. Por lo tanto, para aumentar el C en el suelo se deben aumentar las entradas de enmiendas orgánicas o reducir las pérdidas, es decir las tasas de emisión $\mathrm{C}-\mathrm{CO}_{2}$ debido a la respiración heterotrófica del suelo. Así, el tratamiento T3 fue el de mayor entrada de C orgánico al suelo, pero presentó la menor tasa de $\mathrm{C}$ mineralizado; por el contrario, T2 tuvo una menor entrada de $\mathrm{C}$ orgánico al suelo, pero tuvo una mayor tasa de $\mathrm{C}$ mineralizado, lo que sugiere una eficiente asimilación y aprovechamiento de $\mathrm{C}$ orgánico por parte de la biomasa microbiana del suelo en T2, como fue reportado por Sciubba et al. (2014).

Respecto al valor estimado de la emisión media acumulada de $\mathrm{C}-\mathrm{CO}_{2}$ para los tres tratamientos (Fig. 2), los valores obtenidos tanto para el testigo como para los tratamientos con aplicación de lodos residuales fueron estadísticamente diferentes $(\mathrm{F}=110.57, \mathrm{p}=$ $0.0001)$. Los tratamientos T2 y T3 presentaron incrementos de 16.46 y 21.89 veces en la emisión de $\mathrm{C}-\mathrm{CO}_{2}$ media acumulada con relación al testigo (T1). También se observó que a mayor dosis de aplicación de lodos residuales al suelo sódico, se incrementó la emisión de $\mathrm{C}-\mathrm{CO}_{2}$ media acumulada. Singh (2016) estableció que la sodicidad del suelo influye en la pérdida de su estructura, lo que permite que la materia orgánica en los agregados del suelo se disuelva o disperse y sea más accesible a la descomposición microbiana. Por lo anterior, aun cuando se adiciona materia orgánica al suelo se puede presentar un incremento en la emisión de $\mathrm{C}-\mathrm{CO}_{2}$, pero derivado de la materia orgánica propia del suelo que ha sido disuelta o dispersa y no necesariamente de la materia orgánica adicionada por la enmienda. Esto coincide con el comportamiento del tratamiento T3, que tuvo más emisión de $\mathrm{C}-\mathrm{CO}_{2}$ media acumulada, pero menor porcentaje de mineralización de $\mathrm{C}$ orgánico proveniente de los lodos residuales comparado con T2.

Con relación al comportamiento del $\mathrm{N}$ neto mineralizado $\left(\mathrm{N}_{\min }\right)$, los tratamientos $\mathrm{T} 2$ y $\mathrm{T} 3$, fueron significativamente diferentes $(\mathrm{F}=57, \mathrm{p}=0.0001)$ al testigo T1 (Figs. 3 y 4). Los resultados mostraron que $\mathrm{T} 1$ presentó un incremento paulatino de $\mathrm{N}_{\text {min }}$ durante los 56 días de incubación. Sin embargo, el comportamiento general de la dinámica de $\mathrm{N}_{\min }$ en T2 y T3 fue diferente a T1 (Fig. 3). En el día 3, el valor de $\mathrm{N}_{\min } \mathrm{se}$ estimó en 16.72 y $20.67 \mathrm{mg} / \mathrm{kg}$ para los tratamientos T2 y T3, respectivamente, mientras que en T1, solamente se alcanzó un valor de $\mathrm{N}_{\min }$ de $3.86 \mathrm{mg} / \mathrm{kg}$. El día 7, el valor de $\mathrm{N}_{\min }$ para los tratamientos $\mathrm{T} 2$ y T3 aumento hasta 6.15 y 7.45 veces comparado con T1. Por lo tanto, la aplicación de lodos residuales al suelo sódico incrementó el contenido de $\mathrm{N}$ inorgánico neto como consecuencia de una rápida mineralización de la cantidad y formas de $\mathrm{N}$ presentes, como ha sido reportado en otros estudios (Doublet et al. 2010, Giacomini et al. 2015, Matos et al. 2018). No obstante, el valor de $\mathrm{N}_{\min }$ para $\mathrm{T} 2$ en el día 14 fue muy cercano al valor del día 7 (aproximadamente $33.00 \mathrm{mg}$ / $\mathrm{kg}$ ). En el mismo contexto, el valor de $\mathrm{N}_{\min }$ para $\mathrm{T} 3$ disminuyó de $39.59 \mathrm{mg} / \mathrm{kg}$ (día 7) a $30.63 \mathrm{mg} / \mathrm{kg}$

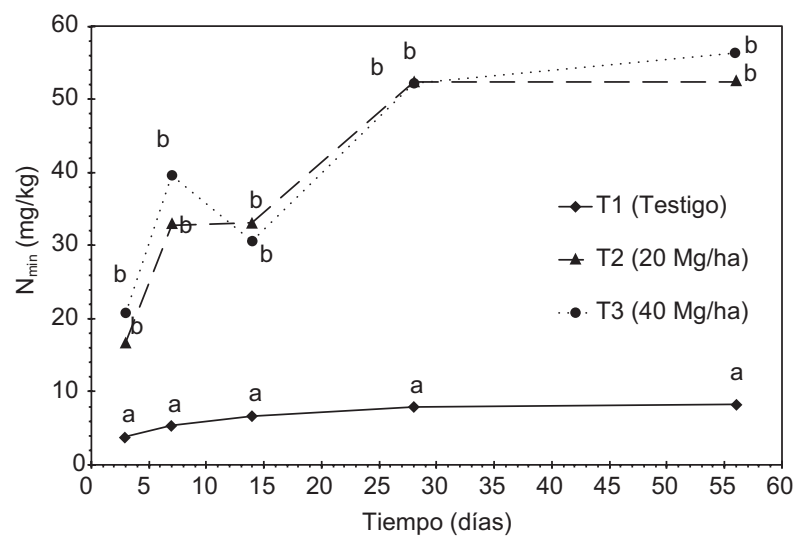

Fig. 3. Dinámica del $\mathrm{N}$ neto mineralizado $\left(\mathrm{N}_{\min }=\mathrm{NH}_{4}{ }^{+}+\right.$ $\mathrm{NO}_{3}{ }^{-}+\mathrm{NO}_{2}{ }^{-}$) en $\mathrm{mg} \mathrm{N} / \mathrm{kg}$ suelo seco durante 56 días de incubación. Las letras diferentes en cada punto de la dinámica indican diferencias significativas $(p \leq 0.05)$ entre tratamientos para cada día de la dinámica 


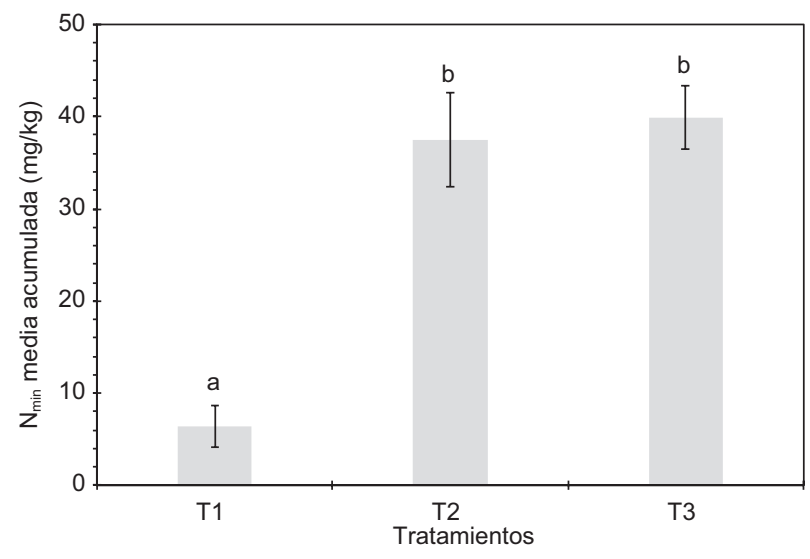

Fig. 4. Media acumulada del $\mathrm{N}$ neto mineralizado $\left(\mathrm{N}_{\min }=\mathrm{NH}_{4}{ }^{+}\right.$ $+\mathrm{NO}_{3}{ }^{-}+\mathrm{NO}_{2}{ }^{-}$) en $\mathrm{mg} \mathrm{N} / \mathrm{kg}$ suelo seco durante 56 días de incubación. Tratamientos: T1 (testigo), T2 (20 Mg/ ha) y T3 $(40 \mathrm{Mg} / \mathrm{ha})$. Las líneas en las barras representan la desviación estándar de las medias acumuladas para cada tratamiento y letras diferentes indican diferencias significativas entre tratamientos $(\mathrm{p} \leq 0.05)$

(día 14). Sin embargo, para el día 28 el valor de $\mathrm{N}_{\min }$ presentó nuevamente un incremento hasta alcanzar valores de 52.43 y $52.21 \mathrm{mg} / \mathrm{kg}$ para T2 y T3, respectivamente. El día 56, los valores de $\mathrm{N}_{\min }$ se estabilizaron en ambos tratamientos (T2 $=52.32 \mathrm{mg} / \mathrm{kg}$ y T3 $=56.41 \mathrm{mg} / \mathrm{kg}$ ). Este patrón de $\mathrm{N}_{\min }$ se ha observado en otros estudios en suelos agrícolas con aplicación de lodos residuales (Hernández et al. 2002, Doublet et al. 2010, Matos et al. 2018), lo cual se atribuyó a nuevas formas de $\mathrm{N}$ en el suelo proporcionadas por los lodos residuales, principalmente compuestos alifáticos y proteicos con diferentes grados de resistencia a la descomposición microbiana autóctona de los suelos estudiados a través del tiempo.

A los 56 días de incubación se mineralizaron el 3.04 y $1.66 \%$ del NT proveniente del lodo residual adicionado al suelo sódico agrícola para T2 y T3, respectivamente. Sin embargo, los porcentajes no fueron significativamente diferentes $(\mathrm{F}=7.07, \mathrm{p}$ $=0.06)$ entre sí. Con la información anterior, se estableció que la mineralización neta del NT en el tratamiento T2 fue 1.83 veces mayor que en T3. No obstante, estos resultados se encuentran por debajo de los reportados en estudios previos a corto plazo (30 a 90 días de incubación) para suelos agrícolas, pero sin perturbación por salinidad o sodicidad. Boeira et al. (2002) encontraron porcentajes de mineralización de 16 a $32 \%$ de $\mathrm{N}$ en un suelo arcilloso enmendado con lodos residuales anaeróbicos en dosis de 3 a 90 $\mathrm{Mg} / \mathrm{ha}$. Giacomini et al. (2015) obtuvieron el $60 \%$ de mineralización del $\mathrm{N}$ orgánico incorporado en lodos residuales aeróbicos adicionados a un suelo arenoso en dosis de $30 \mathrm{Mg} / \mathrm{ha}$. Adicionalmente, un estudio reciente encontró fracciones de nitrógeno orgánico mineralizado entre 63.1 y $85.4 \%$ en un suelo agrícola enmendado con lodos residuales anaeróbicos a una dosis de $500 \mathrm{~kg} / \mathrm{ha} / \mathrm{año}$ de $\mathrm{N}$ total (Matos et al. 2018). Respecto a la media acumulada de $\mathrm{N}_{\min }$ (Fig. 4) se obtuvieron diferencias significativas (F $=38.11, \mathrm{p}=0.0003$ ) de los valores obtenidos en los tratamientos T2 y T3 en comparación con T1. Los tratamientos T2 y T3 presentaron un incremento en la media acumulada de $\mathrm{N}_{\min }$ de 5.56 y 5.90 veces con relación a T1. Adicionalmente, al final de los experimentos, los valores obtenidos en T2 y T3 no presentaron diferencias significativas $(\mathrm{F}=1.19, \mathrm{p}$ $=0.34)$. Con estos resultados, se observó que independientemente de las dosis de aplicación de lodos residuales a suelos sódicos no se observó un cambio significativo en la mineralización del $\mathrm{N}$ orgánico. Lo anterior pudo deberse al estatus de la estructura y composición de la biomasa microbiana en el suelo, que debido a las condiciones de sodicidad, restringen la eficiencia de la mineralización del N (Singh 2016, Trivedi et al. 2017).

Los resultados obtenidos para el C-BM se observan en las figuras 5 y 6. En los tres tratamientos, el $\mathrm{C}-\mathrm{BM}$ presentó diferencias significativas $(\mathrm{F}=25.77$, $\mathrm{p}=0.001)$ durante la dinámica de mineralización del $\mathrm{C}$ en el periodo de incubación (Fig. 5). El día 3, los valores del C-BM en los tratamientos T2 y T3 (51.07 y $56.50 \mathrm{mg} / \mathrm{kg}$, respectivamente) no presentaron diferencias significativas $(\mathrm{F}=9.08, \mathrm{p}=0.03)$ entre ellos, pero si con el testigo $(\mathrm{T} 1=15.62 \mathrm{mg} / \mathrm{kg})$. El día 7 se observó un incremento del valor del C-BM

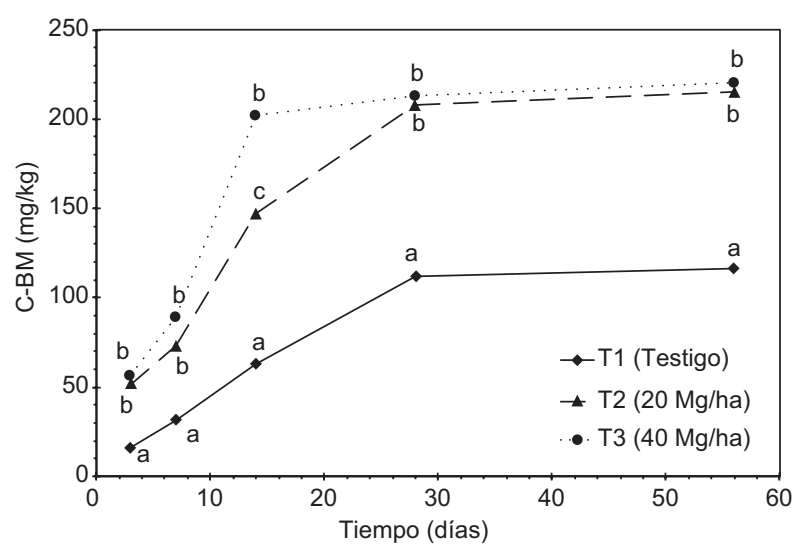

Fig. 5. Dinámica de carbono de la biomasa microbiana (C-BM) en $\mathrm{mg} \mathrm{C}-\mathrm{CO}_{2} / \mathrm{kg}$ suelo seco durante 56 días de incubación. Las letras diferentes en cada punto de la dinámica indican diferencias significativas entre tratamientos $(\mathrm{p} \leq 0.05)$ para cada día de la dinámica 


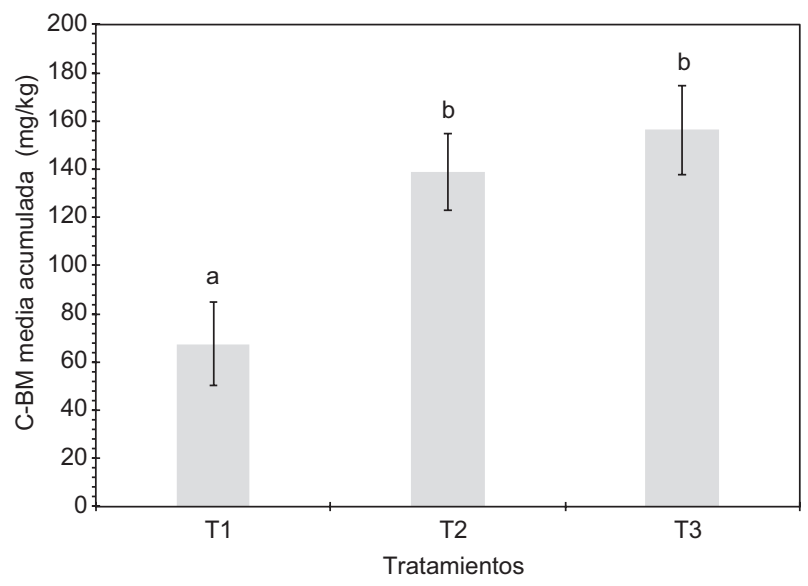

Fig. 6. Media acumulada del carbono de la biomasa microbiana (C-BM media acumulada) en mg C-CO $\mathrm{CO}_{2} / \mathrm{kg}$ suelo seco durante 56 días de incubación. Tratamientos: T1 (testigo), T2 (20 Mg/ha) y T3 (40 Mg/ha). Las líneas en las barras representan la desviación estándar de las medias acumuladas para cada tratamiento y letras diferentes indican diferencias

respecto del valor obtenido en el día 3, de 2.00, 1.43 y 1.58 veces para los tratamientos T1, T2 y T3, respectivamente. En este día, los valores del C-BM en los tratamientos T2 $(72.93 \mathrm{mg} / \mathrm{kg})$ y T3 $(89.00$ $\mathrm{mg} / \mathrm{kg})$ no fueron significativamente diferentes $(\mathrm{F}=$ $2.16, \mathrm{p}=0.22)$ entre ellos, pero sí con el testigo (T1 $=31.38 \mathrm{mg} / \mathrm{kg})(\mathrm{F}=11.10, \mathrm{p}=0.009)$. Los valores deL C-BM en el día 14 fueron significativamente diferentes $(\mathrm{F}=48.54, \mathrm{p}=0.0001)$ entre los tratamientos T1 $(62.69 \mathrm{mg} / \mathrm{kg})$, T2 (147.07 mg/kg) y T3 $(202.23$ $\mathrm{mg} / \mathrm{kg}$ ). Al día 28, los valores obtenidos de C-BM para los tratamientos T2 y T3 fueron de 207.87 y $213.2 \mathrm{mg} / \mathrm{kg}$, y no presentaron diferencias estadísticas $(\mathrm{F}=0.51, \mathrm{p}=0.51)$ entre sí. $\mathrm{El} \mathrm{C}-\mathrm{BM}$ en $\mathrm{T} 1$ para el mismo periodo fue de $111.62 \mathrm{mg} / \mathrm{kg}$, siendo más bajo y estadísticamente diferente $(\mathrm{F}=25.71, \mathrm{p}$ $=0.001)$ a los tratamientos T2 y T3. En este tiempo se observó un efecto importante de la aplicación y mineralización del $\mathrm{C}$ orgánico proveniente de lodos residuales sobre el contenido de C-BM. En el día 56 los valores de C-BM fueron muy similares al día 28 para los tratamientos con aplicación de lodos residuales T2 $(214.87 \mathrm{mg} / \mathrm{kg})$ y T3 $(220.33 \mathrm{mg} / \mathrm{kg})$. En el día 56 el C-BM no fue estadísticamente diferente $(\mathrm{F}=0.51, \mathrm{p}=0.51)$ entre los tratamientos $\mathrm{T} 2$ y T3, pero sí con referencia a T1 $(116.02 \mathrm{mg} / \mathrm{kg})(\mathrm{F}$ $=28.16, \mathrm{p}=0.0009$ ).

Los valores de la media acumulada del contenido de C-BM en los tratamientos T1, T2 y T3 durante los 56 días de dinámica fueron de 67.47, 138.76 y $156.25 \mathrm{mg} / \mathrm{kg}$, respectivamente (Fig. 6). Los valores de la media acumulada del C-BM para los tratamientos $\mathrm{T} 2$ y $\mathrm{T} 3$, fueron significativamente diferentes al testigo $\mathrm{T} 1(\mathrm{~F}=24.09, \mathrm{p}=0.001)$ pero no entre sí. Los valores del C-BM obtenidos en este estudio fueron similares a los reportados por Fernandes et al. (2005), Wong et al. (2009) y Matos et al. (2018), lo cual establece que la aplicación de lodos residuales al suelo favorece un incremento en el C-BM; asimismo, estimula la actividad microbiana y enzimática debido a la presencia de las fracciones de materia orgánica o formas de $\mathrm{C}$ orgánico fácilmente asimilables presentes en los lodos residuales. El porcentaje de inmovilización del $\mathrm{C}$ orgánico por la biomasa microbiana en los suelos con aplicación de lodos residuales se obtuvo mediante la diferencia entre la media acumulada del C-BM de los tratamientos T2 y T3 y la media acumulada del C-BM del tratamiento T1, de la cual se obtuvieron porcentajes de 0.81 y $0.50 \%$ para T2 y T3, respectivamente. Estos porcentajes se encuentran dentro del intervalo obtenido por Fernandes et al. (2005) con valores entre 0.40 y $0.90 \%$ de $\mathrm{C}$ microbiano asimilado en suelos arcillosos de Brasil enmendados con lodos residuales provenientes de un tratamiento biológico secundario de aguas residuales. Sin embargo, este fenómeno también ha sido relacionado con el aumento en la cantidad y calidad de materia orgánica del lodo residual que ingresa en el suelo, como se ha establecido en otros estudios (Hu et al. 2011, Araújo et al. 2015). En el mismo contexto, el tratamiento T2, presentó una mayor inmovilización del $\mathrm{C}$ orgánico de lodos residuales hacia el C-BM comparado con el tratamiento T3. Estos resultados no coinciden con lo establecido por Scciuba et al. (2014), quienes establecieron que a un aumento en la tasa de aplicación de lodos residuales existió un aumento en el valor del C-BM. Esto puede ser consecuencia del tipo de suelo utilizado, ya que el suelo que se analizó en el presente trabajo es arcilloso, alcalino y sódico, mientras que el utilizado por Scciuba et al. (2014) era franco arenoso, neutro y sin problemas de sodicidad. Singh (2016) estableció que la biomasa microbiana y su actividad pueden disminuir en suelos sódicos con aplicación de materia orgánica fresca, como podrían ser los lodos residuales. Sin embargo, para elucidar los niveles y mecanismos de afectación a nivel de la biomasa microbiana como tal, se requieren estudios adicionales con el uso de herramientas de biología molecular. De esta manera podrían elucidarse posibles cambios en la estructura y función de las comunidades microbianas en suelos sódicos durante la adición de lodos residuales (Domínguez-Mendoza et al. 2014, Gómez-Acata et al. 2017, León-Lorenzana et al. 2018). 
El comportamiento de la AEM-FDA para los tres tratamientos se observa en las figuras 7 y 8 . En general, la AEM-FDA, presentó diferencias significativas $(\mathrm{F}=27.53, \mathrm{p}=0.0005)$ entre tratamientos durante la dinámica de mineralización evaluada a 56 días (Fig. 7). La AEM-FDA fue mayor para los tratamientos con aplicación de lodos residuales a lo largo de las dinámicas. En el día 3, los tratamientos T1, T2 y T3 presentaron valores de AEM-FDA de $92.14,216.01$ y $235.59 \mathrm{mg} / \mathrm{kg} / \mathrm{h}$, respectivamente, lo que representó un incremento de 2.34 y 2.56 veces para T2 y T3 en comparación con T1. Los valores de AEM-FDA obtenidos en los tratamientos T2 y $\mathrm{T} 3$ no fueron diferentes estadísticamente $(\mathrm{F}=0.54$, $\mathrm{p}=0.50)$ entre sí, pero sí con relación al testigo $\mathrm{T} 1$ $(\mathrm{F}=21.32, \mathrm{p}=0.0003)$ para este día. En el día $7 \mathrm{se}$ registraron valores de AEM-FDA en T1, T2 y T3 de $81.96,212.54$ y $294.27 \mathrm{mg} / \mathrm{kg} / \mathrm{h}$, respectivamente. Lo anterior representó un incremento de 2.59 y 3.59 veces para los tratamientos T2 y T3 con relación a T1. En el mismo periodo se obtuvieron los valores más altos de AEM-FDA en los tratamientos con aplicación de lodos residuales; dichos valores fueron además significativamente diferentes $(\mathrm{F}=50.03, \mathrm{p}$ $=0.0002$ ) entre los tres tratamientos. En el día 14, los valores de AEM-FDA fueron de 59.93, $168.40 \mathrm{y}$ $215.35 \mathrm{mg} / \mathrm{kg} / \mathrm{h}$ para los tratamientos T1, T2 y T3, respectivamente; aun cuando fueron más bajos en comparación con el día 3 , en este periodo se observó un incremento en la AEM-FDA en los tratamientos con lodos residuales (T2 y T3) de 2.81 y 3.59 veces respecto a T1. No obstante, en el día 14 los valores

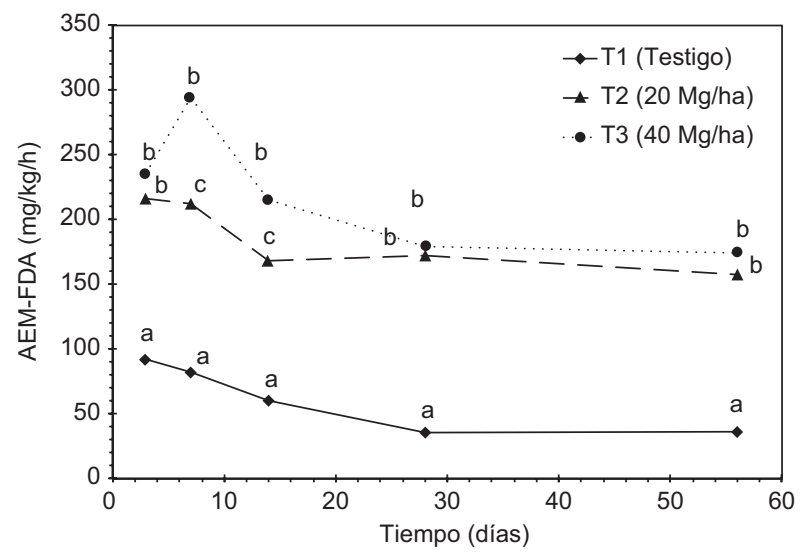

Fig. 7. Dinámica de la actividad enzimática microbiana por hidrólisis de diacetato de fluoresceína (AEM-FDA) expresada en mg FDA hidrolizado/ $\mathrm{kg}$ suelo seco/h durante 56 días de incubación. Letras diferentes en cada punto de las líneas indican diferencias significativas entre tratamientos para cada día de la dinámica $(\mathrm{p} \leq 0.05)$ de AEM-FDA disminuyeron en los tres tratamientos con relación a los que se obtuvieron en los días 3 y 7. Los valores obtenidos el día 14 fueron significativamente diferentes $(\mathrm{F}=8.81, \mathrm{p}=0.04)$ entre los tres tratamientos. En los días 28 y 56 se obtuvieron valores de AEM-FDA del orden de 35.53 y 36.00 $\mathrm{mg} / \mathrm{kg} / \mathrm{h}$ para $\mathrm{T} 1$; de 171.79 y $157.57 \mathrm{mg} / \mathrm{kg} / \mathrm{h}$ para T2; y de 179.08 y $174.05 \mathrm{mg} / \mathrm{kg} / \mathrm{h}$ para T3, respectivamente. Los incrementos de la AEM-FDA en los días 28 y 56 fueron de 4.83 y 4.38 veces para T2 y de 5.04 y 4.83 veces para T3, en comparación con T1. En este periodo, la AEM-FDA se mantuvo estable en cada tratamiento, es decir, no hubo ni incrementos ni decrementos drásticos para ninguno de los tratamientos; sin embargo, los tratamientos T2 y T3 presentaron diferencias significativas con relación a T1 para los días $28(\mathrm{~F}=42.24, \mathrm{p}=0.0003)$ y $56(\mathrm{~F}=26.74, \mathrm{p}=0.001)$. Con estos resultados se observó una AEM-FDA mayor en los tratamientos con aplicación de lodos residuales (T2 y T3) respecto del testigo (T1), debido probablemente al efecto estimulante de la descomposición de los lodos residuales aplicados.

Lo anterior coincide con lo reportado por FrancoOtero et al. (2012), Lu et al. (2015) y Bhaduri et al. (2016), quienes establecieron que la estimulación reflejó una demanda mayor de $\mathrm{C}$ para el mantenimiento celular y un uso de energía menos eficiente. Además, se evidenció un incremento significativo de la AEM-FDA en el día 7 para el tratamiento T3. La AEM-FDA presentó una disminución paulatina en los tratamientos T1 y T2 desde el inicio de la dinámica (día 3) hasta el final de ésta (día 56). Lo anterior puede deberse a que la dosis de aplicación de lodos residuales fue menor para T2 y estuvo ausente en T1 con relación a T3, por lo cual no hubo aumento en el contenido de sustancias poliméricas extracelulares exógenas al suelo. Se sabe que una mayor dosis de aplicación se refleja en un incremento de la AEM-FDA en el corto plazo, como han reportado otros autores (Scciuba et al. 2014, Ferreira et al. 2016). Sciubba et al. (2014) establecieron que la dosis de aplicación de lodos residuales aeróbicos a suelos agrícolas tiene un impacto significativo en indicadores de calidad del suelo, especialmente en la tasa de respiración, la biomasa microbiana y las actividades enzimáticas, a consecuencia del tipo de sustrato y la complejidad de las moléculas que lo conforman. Asimismo, dichos autores enfatizaron que la actividad enzimática expresada como hidrólisis de FDA es un indicador útil para dar una respuesta rápida a las variaciones del sistema causadas por la aplicación de lodos residuales. 
En relación con la media acumulada de la AEMFDA, los tratamientos T2 y T3 fueron significativamente diferentes $(\mathrm{F}=7.50, \mathrm{p}=0.0001)$ del tratamiento T1 (Fig. 8), el cual presentó una media acumulada de $61.11 \mathrm{mg} / \mathrm{kg} / \mathrm{h}$, mientras que los tratamientos T2 y T3 obtuvieron una actividad enzimática media acumulada de 185.26 y $219.67 \mathrm{mg} / \mathrm{kg} / \mathrm{h}$, respectivamente, y fueron 3.03 y 3.59 veces mayores respecto del valor obtenido en el testigo T1. Esta dinámica coincide con lo reportado en otros estudios sobre un efecto positivo en las actividades enzimáticas del suelo al adicionar materia orgánica a diferentes dosis, también en un periodo de tiempo corto (Tejada et al.

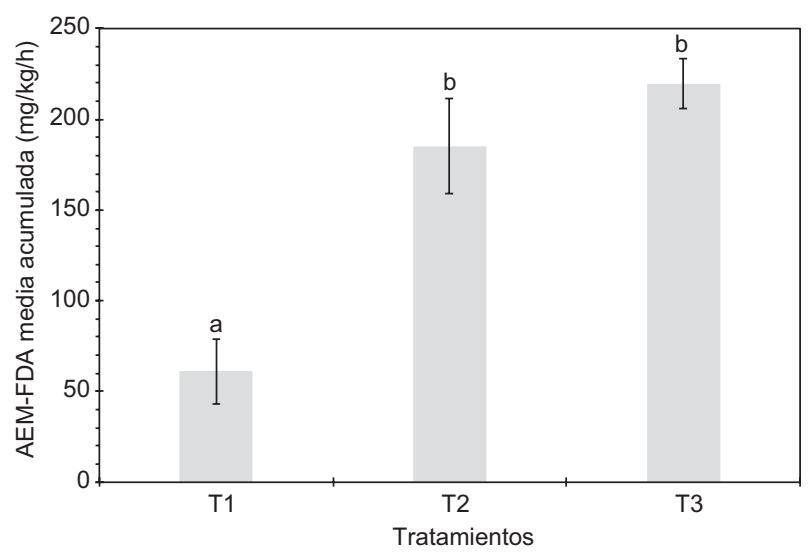

Fig. 8. Media acumulada de la actividad enzimática microbiana por hidrólisis de diacetato de fluoresceína (AEM-FDA) expresada en mg FDA hidrolizado/kg suelo seco/h durante 56 días de incubación. Tratamientos: T1 (testigo), T2 (20 Mg/ha) y T3 (40 Mg/ha). Las líneas en las barras representan la desviación estándar de las medias acumuladas para cada tratamiento y las letras diferentes en las barras indican diferencias significativas entre tratamientos $(\mathrm{p} \leq 0.05)$
2006, Franco-Otero et al. 2012, Sciubba et al. 2014, Lu et al. 2015, Wang et al. 2017).

En el cuadro II, se observan los indicadores biológicos de calidad del suelo $\mathrm{qCO}_{2}, \mathrm{qFDA}$ y $\mathrm{N}_{\text {min }} / \mathrm{C}_{\text {mic }}$ determinados durante la dinámica de mineralización de lodos residuales en el suelo sódico evaluado. El coeficiente metabólico $\mathrm{qCO}_{2}$ se incrementó con la adición de lodos residuales al inicio de la dinámica para todos los tratamientos y disminuyó con relación al tiempo. No obstante, el $\mathrm{qCO}_{2}$ presentó diferencias significativas $(\mathrm{F}=27.67, \mathrm{p}=0.001)$ en los tratamientos T2 y T3 con referencia a T1. Asimismo, únicamente se presentó un valor de $\mathrm{qCO}_{2}$ estadísticamente diferente $(\mathrm{F}=35.28, \mathrm{p}=0.004)$ en los tratamientos $\mathrm{T} 2$ y $\mathrm{T} 3$ en el día 3 de la dinámica. $\mathrm{El} \mathrm{qCO}_{2}$ ha sido considerado un importante parámetro para interpretar la actividad microbiana en condiciones de estrés, o cambios bruscos en su ecología; además, refleja los requerimientos energéticos de los microorganismos para mantener su actividad metabólica, principalmente para la síntesis de biomasa (Nannipieri et al. 2003, Roohi et al. 2016). Valores altos de $\mathrm{qCO}_{2}$ indican por lo general la presencia de una alteración ecológica, así como efectos tóxicos y mayor actividad del ecosistema, es decir, los microorganismos del suelo emiten más $\mathrm{C}-\mathrm{CO}_{2}$ por unidad de biomasa por unidad de tiempo a medida que aumenta el estrés (Anderson y Domsch 1993, Araújo et al. 2016).

Los resultados sugieren que la aplicación a mayor dosis de lodos residuales en suelo sódico incrementa los valores de $\mathrm{qCO}_{2}$, como respuesta inmediata al estrés de los microorganismos del suelo. Esto se debe a los cambios que podría sufrir la población microbiana por las sustancias poliméricas extracelulares adicionadas con los lodos residuales al suelo sódico; sin embargo, el incremento de $\mathrm{qCO}_{2}$ también podría

CUADRO II. INDICADORES BIOLÓGICOS DE CALIDAD DEL SUELO DURANTE EL EXPERIMENTO DE INCUBACIÓN DE SUELO SÓDICO ENMENDADO CON LODOS RESIDUALES

\begin{tabular}{|c|c|c|c|c|c|c|c|c|c|}
\hline \multirow{3}{*}{ Días } & \multicolumn{9}{|c|}{ Tratamiento } \\
\hline & $\mathrm{T} 1$ & $\mathrm{~T} 2$ & $\mathrm{~T} 3$ & T1 & $\mathrm{T} 2$ & $\mathrm{~T} 3$ & T1 & $\mathrm{T} 2$ & $\mathrm{~T} 3$ \\
\hline & \multicolumn{3}{|c|}{$\mathrm{qCO}_{2}\left(\mathrm{mg} \mathrm{C}-\mathrm{CO}_{2} / \mathrm{mg} \mathrm{C}_{\mathrm{mic}} / \mathrm{h}\right)$} & \multicolumn{3}{|c|}{ qFDA (mg FDA hidrolizado/mg $\mathrm{C}_{\mathrm{mic}} / \mathrm{h}$ ) } & \multicolumn{3}{|c|}{$\mathrm{N}_{\min } / \mathrm{C}_{\text {mic }} \mathrm{mg} \mathrm{N}_{\min } / \mathrm{mg} \mathrm{C}_{\text {mic }}$} \\
\hline 3 & $0.799 \mathrm{a}$ & $2.286 b$ & $4.035 \mathrm{c}$ & $0.039 \mathrm{a}$ & $0.042 \mathrm{a}$ & $0.042 \mathrm{a}$ & $1.664 \mathrm{a}$ & $3.274 b$ & $3.660 \mathrm{~b}$ \\
\hline 7 & $0.188 \mathrm{a}$ & $1.981 b$ & $2.274 b$ & $0.018 \mathrm{a}$ & $0.030 \mathrm{~b}$ & $0.034 b$ & $1.174 \mathrm{a}$ & $4.568 b$ & $4.559 b$ \\
\hline 14 & $0.081 \mathrm{a}$ & $0.761 b$ & $0.838 b$ & $0.006 \mathrm{a}$ & $0.011 \mathrm{a}$ & $0.011 \mathrm{a}$ & $0.713 \mathrm{a}$ & $2.253 b$ & $2.525 b$ \\
\hline 28 & $0.023 \mathrm{a}$ & $0.359 b$ & $0.428 b$ & $0.002 \mathrm{a}$ & $0.008 \mathrm{a}$ & $0.008 \mathrm{a}$ & $0.469 \mathrm{a}$ & $2.527 \mathrm{~b}$ & $2.449 \mathrm{~b}$ \\
\hline 56 & $0.011 \mathrm{a}$ & $0.183 b$ & $0.210 \mathrm{~b}$ & $0.002 \mathrm{a}$ & $0.007 \mathrm{a}$ & $0.008 \mathrm{a}$ & $0.472 \mathrm{a}$ & $2.449 b$ & $2.560 \mathrm{~b}$ \\
\hline
\end{tabular}

Tratamientos: T1: suelo sin lodo (testigo), T2: suelo más lodo en dosis de $20 \mathrm{Mg} /$ ha y T3: suelo más lodo en dosis de $40 \mathrm{Mg} / \mathrm{ha}$; $\mathrm{qCO}$ : cociente metabólico microbiano, qFDA: actividad hidrolítica específica, $\mathrm{N}_{\min }$ : nitrógeno neto mineralizado $\left(\mathrm{N}_{\min }=\mathrm{NH}_{4}{ }^{+}+\mathrm{NO}_{3}{ }^{-}+\mathrm{NO}_{2}{ }^{-}\right)$, $\mathrm{C}_{\text {mic }}$ : carbono microbianoLetras diferentes en la misma fila son estadísticamente diferentes $(\mathrm{p} \leq 0.05)$ para cada parámetro determinado 
relacionarse con el aumento de la actividad microbiana por incremento del efecto tóxico de compuestos orgánicos recalcitrantes en los lodos residuales, como se ha sugerido en estudios previos (Roohi et al. 2016, de Sousa et al. 2017). Por otro lado, la tendencia general a disminuir el valor de $\mathrm{qCO}_{2}$ respecto al tiempo, en los diferentes tratamientos, puede deberse a que, durante los procesos de mineralización de $\mathrm{C}$ y $\mathrm{N}$ de la materia orgánica adicionada, se vayan generando contenidos o formas de C orgánico más asequibles para la descomposición microbiana; esto aliviaría el estrés o alteraciones ecológicas en la población microbiana del suelo sódico, como han descrito Trivedi et al. (2017). Por lo tanto, el $\mathrm{qCO}_{2}$ disminuyó a medida que el C-BM aumentó (Fig. 5), a pesar de las condiciones desfavorables que presenta un suelo sódico. Resultados similares al comportamiento del $\mathrm{qCO}_{2}$ fueron reportados por Wong et al. (2009) en suelos salinos y sódicos enmendados con yeso y materia orgánicos.

En cuanto al índice qFDA, éste se ha utilizado principalmente para elucidar el efecto tóxico de compuestos xenobióticos, como herbicidas, sobre la microbiota de los suelos (Perucci et al. 2000, Sofo et al. 2012). En este estudio, sólo en el día 7 de la dinámica el índice qFDA fue mayor en los tratamientos T2 y T3 con relación al testigo (T1) (Cuadro II). Además, los resultados destacan que, con el tiempo de incubación, disminuyó el índice qFDA para todos los tratamientos, lo que refleja una estabilización o estancamiento en la actividad metabólica de la microbiota, así como un incremento del C-BM en el suelo. Sánchez-Monedero et al. (2008) establecieron que el qFDA permanece prácticamente sin cambios durante la dinámica de mineralización de diferentes enmiendas orgánicas frescas evaluadas, entre ellas una mezcla de lodos residuales $(38 \%)$ con residuos de algodón $(62 \%)$. De acuerdo con los resultados anteriores, se puede mencionar que es prometedor utilizar este índice, basado en la determinación de actividades hidrolíticas microbianas y la biomasa microbiana, para evaluar en general la calidad de los suelos agrícolas y su historial de manejo; asimismo, para determinar efectos positivos o negativos a corto plazo en suelos sódicos como resultado de la aplicación y mineralización de enmiendas orgánicas con diferentes formas de $\mathrm{C}$ y $\mathrm{N}$ (por ejemplo, lodos residuales).Por último, el cociente entre el $\mathrm{N}_{\min }$ y el C-BM $\left(\mathrm{N}_{\min } / \mathrm{C}_{\mathrm{mic}}\right)$, que establece el efecto de la aplicación de lodos residuales sobre la mineralización de $\mathrm{N}$ orgánico por unidad de C-BM (Cuadro II), indicó que en los tratamientos T2 y T3 los valores son mayores durante la dinámica con relación a lo obtenido para T1. Igualmente, los resultados mostraron diferencias significativas $(\mathrm{F}=8.52, \mathrm{p}=0.005)$ de T2 y T3, comparados con T1, pero sin diferencias entre ellos durante la dinámica. Con estos resultados referentes a la dosis de aplicación de lodos residuales a suelo sódico, se reiteró que no se observó un efecto significativo sobre la mineralización del $\mathrm{N}$ orgánico, pero sí en la mineralización de $\mathrm{C}$ orgánico.

\section{CONCLUSIONES}

La aplicación de lodos residuales al suelo sódico tuvo un efecto positivo sobre la mineralización del $\mathrm{C}$ a corto plazo, reflejado en un incremento en la tasa de respiración (emisiones de $\mathrm{C}-\mathrm{CO}_{2}$ ), así como en el C-BM y la AEM-FDA. Por lo tanto, se observó un efecto bioestimulante de la aplicación y calidad de la materia orgánica en descomposición. Las dosis de aplicación de lodos residuales al suelo sódico no tuvieron efecto sobre la mineralización del $\mathrm{N}$ orgánico, a través de las tasas de mineralización $\mathrm{N}_{\text {min }}$ como testigo.

Los indicadores biológicos de la calidad del suelo evaluados confirmaron una estimulación de la biomasa y actividad microbiana reflejada en el $\mathrm{qCO}_{2}$, qFDA y $\mathrm{N}_{\text {min }} / \mathrm{C}_{\text {mic }}$ en los tratamientos con aplicación de lodos residuales con relación al tratamiento testigo a corto plazo. Estos indicadores fueron útiles para destacar los efectos en la biomasa y actividades microbianas durante la aplicación de lodos residuales al suelo sódico por su pronta respuesta, pero no respecto de la dosificación de lodos residuales.

\section{AGRADECIMIENTOS}

A la Secretaría de Educación Pública (SEP) por el "Apoyo para el fortalecimiento de cuerpos académicos" núm. IDCA 23626, otorgado al cuerpo académico ITC-CA-18. Igualmente, al Consejo Nacional de Ciencia y Tecnología (CONACyT) por su apoyo como parte del proyecto financiado por la Secretaría de Educación Pública (SEP-CONACyT) con clave: $236674,2015-2019$, y por la beca otorgada para estudios de posgrado núm. 212522.

\section{REFERENCIAS}

Adam G. y Duncan H. (2001). Development of a sensitive and rapid method for the measurement of total microbial activity using fluorescein diacetate (FDA) in a range of soils. Soil Biol. Biochem. 33 (7-8), 943951. https://doi.org/10.1016/S0038-0717(00)00244-3 
Anderson J.P.E. y Domsch K.H. (1978). A physiological method for the quantitative measurement of microbial biomass in soils. Soil Biol. Biochem. 10 (3), 215-221. https://doi.org/10.1016/0038-0717(78)90099-8

Anderson T.H. y Domsch K.H. (1990). Application of ecophysiological quotients $\left(\mathrm{qCO}_{2}\right.$ and $\left.\mathrm{qD}\right)$ on microbial biomasses from soils of different cropping histories. Soil Biol. Biochem. 22 (2), 251-255. https://doi. org/10.1016/0038-0717(90)90094-G

Anderson T.H. y Domsch, K. H. (1993). The metabolic quotient for $\mathrm{CO}_{2}\left(\mathrm{qCO}_{2}\right)$ as a specific activity parameter to assess the effects of environmental conditions, such as $\mathrm{pH}$, on the microbial biomass of forest soils. Soil Biol. Biochem. 25 (3), 393-395. https://doi. org/10.1016/0038-0717(93)90140-7

Araújo A.S.F., Miranda A.R.L., Oliveira M.L.J., Santos V.M., Nunes L.A.P.L. y Melo W.J. (2015). Soil microbial properties after 5 years of consecutive amendment with composted tannery sludge. Environ. Monit. Assess. 187 (1), 4153. https://doi.org/10.1007/ s10661-014-4153-3

Araújo A.S.F., Lima L.M., Santos V.M. y Schmidt R. (2016). Repeated application of composted tannery sludge affects differently soil microbial biomass, enzymes activity, and ammonia-oxidizing organisms. Environ. Sci. Pollut. R. 23 (19), 19193-9200. https:// doi.org/10.1007/s11356-016-7115-1

Beltrán-Hernández R.I., Luna-Guido M.L. y Dendooven L. (2007). Emission of carbon dioxide and dynamics of inorganic $\mathrm{N}$ in a gradient of alkaline saline soils of the former lake Texcoco. Appl. Soil Ecol. 35 (2), 390-403. https://doi.org/10.1016/j.apsoil.2006.07.005

Bhaduri D., Saha A., Desai D. y Meena H.N. (2016). Restoration of carbon and microbial activity in salt-induced soil by application of peanut shell biochar during short-term incubation study. Chemosphere 148, 86-98. https://doi.org/10.1016/j.chemosphere.2015.12.130

Blake G.R. y Hartge, K.H. (1986). Bulk density. En: Methods of soil analysis: Part 1 - physical and mineralogical methods (Klute A., Ed.). Soil Science Society of America, Madison, WI, EUA, 363-375. https://doi. org/10.2136/sssabookser5.1.2ed.c13

Błońska E., Lasota J. y Zwydak M. (2017). The relationship between soil properties, enzyme activity and land use. Forest Research Papers 78 (1), 39-44. https://doi. org/10.1515/frp-2017-0004

Boeira R.C., Ligo M.A.V. y Dynia J.F. (2002). Mineralização de nitrogênio em solo tropical tratado com lodos de esgoto. Pesqui. Agropecu. Bras. 37 (11), 1639-1647. https://doi.org/10.1590/S0100-204X2002001100016

Bremner J.M. (1996). Nitrogen - total. En: Methods of soil analysis: Part 3 - chemical methods (Sparks D.L., Ed.). Soil Science Society of America, Madison,
WI, EUA, pp. 1085-1121. https://doi.org/10.2136/ sssabookser5.3.c37

Celis J.E., Sandoval M., Martínez B. y Quezada C. (2013). Effect of organic and mineral amendments upon soil respiration and microbial biomass in a saline-sodic soil. Cienc. Investig. Agrar. 40 (3), 571-580. https:// doi.org/10.4067/S0718-16202013000300010

Conde E., Cárdenas M., Ponce-Mendoza A., Luna-Guido M.L., Cruz-Mondragón C. y Dendooven L. (2005). The impacts of inorganic nitrogen application on mineralization of 14C-labelled maize and glucose, and on priming effect in saline alkaline soil. Soil Biol. Biochem. 37, 681-691. https://doi.org/10.1016/j. soilbio.2004.08.026

De Sousa R.S., Santos V.M., de Melo W.J., Nunes L.A.P.L., van den Brink P.J. y Araújo A.S.F. (2017). Timedependent effect of composted tannery sludge on the chemical and microbial properties of soil. Ecotoxicology 26 (10), 1366-1377. https://doi.org/10.1007/ s10646-017-1861-9

Domínguez-Mendoza C.A., Bello-López J.M., NavarroNoya Y.E., de León-Lorenzana A.S., DelgadoBalbuena L., Gómez-Acata S., Ruíz-Valdiviezo V.M., Ramirez-Villanueva D.A., Luna-Guido M. y Dendooven L. (2014). Bacterial community structure in fumigated soil. Soil Biol. Biochem. 73, 122-129. https://doi.org/10.1016/j.soilbio.2014.02.012

Doublet J., Francou C., Pétraud J.P., Dignac M.F., Poitrenaud M. y Houot S. (2010). Distribution of C and N mineralization of a sludge compost within particle-size fractions. Bioresource Technol. 101 (4), 1254-1262. https://doi.org/10.1016/j.biortech.2009.09.037

Edwards J., Othman M., Crossin E. y Burn S. (2017). Anaerobic co-digestion of municipal food waste and sewage sludge: a comparative life cycle assessment in the context of a waste service provision. Bioresource Technol. 223, 237-249. https://doi.org/10.1016/j. biortech.2016.10.044

Fernandes S.A.P., Bettiol W. y Cerri C.C. (2005). Effect of sewage sludge on microbial biomass, basal respiration, metabolic quotient and soil enzymatic activity. Appl. Soil Ecol. 30 (1), 65-77. https://doi.org/10.1016/j. apsoil.2004.03.008

Ferreira A.C.C., Leite L.F.C., Araújo A.S.F. y Eisenhauer N. (2016). Land-use type effects on soil organic carbon and microbial properties in a semi-arid region of northeast Brazil. Land Degrad. Dev. 27 (2), 171-178. https://doi.org/10.1002/ldr.2282

Ferreras L.A., Toresani S., Faggioli V. y Galarza C. (2015). Sensibilidad de indicadores biológicos edáficos en un Argiudol de la Región Pampeana Argentina. Spanish Journal of Soil Science 5 (3), 220. https://doi. org/10.3232/SJSS.2015.V5.N3.04 
Franco-Otero V.G., Soler-Rovira P., Hernández D., Lópezde-Sá E.G. y Plaza C. (2012). Short-term effects of organic municipal wastes on wheat yield, microbial biomass, microbial activity, and chemical properties of soil. Biol. Fert. Soils 48 (2), 205-216. https://doi. org/10.1007/s00374-011-0620-y

Gajda A.M., Czyż E.A., Dexter A.R., Furtak K.M., Grządziel J. y Stanek-Tarkowska J. (2018). Effects of different soil management practices on soil properties and microbial diversity. Int. Agrophys. 32 (1), 81-91. https://doi.org/10.1515/intag-2016-0089

Gee G.W. y Bauder J.W. (1986). Particle size analysis. En: Methods of soil analysis: Part 1 - physical and mineralogical methods (Klute A., Ed.). Soil Science Society of America, Madison, WI, EUA, 383-411. https://doi. org/10.2136/sssabookser5.1.2ed.c15

Giacomini S.J., Simon V.L.G., Aita C., Bastos L.M., Weiler D.A. y Redin M. (2015). Carbon and nitrogen mineralization in soil combining sewage sludge and straw. Rev. Bras. Cienc. Solo 39 (5), 1428-1435. https://doi. org/10.1590/01000683rbcs20140324

Gómez-Acata S., Esquivel-Ríos I., Pérez-Sandoval M.V., Navarro-Noya Y., Rojas-Valdez A., Thalasso F., LunaGuido M. y Dendooven L. (2017). Bacterial community structure within an activated sludge reactor added with phenolic compounds. Appl. Microbiol. Biot. 101 (8), 3405-3414. https://doi.org/10.1007/s00253-016-8000-z

Hernández T., Moral R., Pérez-Espinosa A., MorenoCaselles J., Pérez-Murcia M.D. y García C. (2002). Nitrogen mineralisation potential in calcareous soils amended with sewage sludge. Bioresource Technol. 83 (3), 213-219. https://doi.org/10.1016/S09608524(01)00224-3

Hu J., Lin X., Wang J., Dai J., Chen R., Zhang J. y Wong M.H. (2011). Microbial functional diversity, metabolic quotient, and invertase activity of a sandy loam soil as affected by long-term application of organic amendment and mineral fertilizer. J. Soil. Sediment. 11 (2), 271-280. https://doi.org/10.1007/s11368-010-0308-1

Iranpour R., Cox H.H.J., Kearney, R.J., Clark, J.H., Pincince A.B. y Daigger G. T. (2004). Regulations for biosolids land application in US and European Union. J. Residuals Sci. Tech. 1 (4), 209-222. https:// doi.org/10.2175/193864703784292340

Jurado-Guerra P., Luna-Luna M. y Barretero-Hernández R. (2004). Aprovechamiento de biosólidos como abonos orgánicos en pastizales áridos y semiáridos. Rev. Mex. Cienc. Pecu. 42 (3), 379-395

Jurado P., Arredondo T., Flores E., Olalde V. y Frías, J. (2007). Efecto de los biosólidos sobre la humedad y los nutrimentos del suelo y la producción de forraje en pastizales semiáridos. Terra Latinoamericana, 25 (2), 211-218.
Kelly J.J., Policht K., Grancharova T. y Hundal L.S. (2011). Distinct responses in ammonia-oxidizing archaea and bacteria after addition of biosolids to an agricultural soil. Appl. Environ. Microb. 77, 65516558. https://doi.org/10.1128/AEM.02608-10

Larney F.J. y Angers D.A. (2012). The role of organic amendments in soil reclamation: A review. Can. J. Soil Sci. 92 (1), 19-38. https://doi.org/10.4141/cjss010-064

León-Lorenzana D., Seleny A., Delgado-Balbuena L., Domínguez-Mendoza C.A., Navarro-Noya Y.E., Luna-Guido M. y Dendooven L. (2018). Soil salinity controls relative abundance of specific bacterial groups involved in the decomposition of maize plant residues. Front. Ecol. Evol. 6, 51. https://doi.org/10.3389/ fevo.2018.00051

Liew A.G., Idris A., Wong C.H., Samad A.A., Noor M.J.M. y Baki A.M. (2004). Incorporation of sewage sludge in clay brick and its characterization. Waste Manage. Res. 22 (4), 226-233. https://doi. org/10.1177/0734242X04044989

Lu H., Lashari M.S., Liu X., Ji H., Li L., Zheng J., Kibue G.W., Joseph S. y Pan G. (2015). Changes in soil microbial community structure and enzyme activity with amendment of biochar-manure compost and pyroligneous solution in a saline soil from Central China. Eur. J. Soil Biol. 70, 67-76. https://doi.org/10.1016/j. ejsobi.2015.07.005

Matos A.T., Diniz I.C., Matos M.P., Borges A.C. y Pereira A.A. (2018). Degradation rate of anaerobically digested sewage sludge in soil. J. Water Sanit. Hyg. De. 8 (1), 17-26. https://doi.org/10.2166/washdev.2017.138

Mavi M.S., Marschner P., Chittleborough D.J., Cox J.W. y Sanderman J. (2012). Salinity and sodicity affect soil respiration and dissolved organic matter dynamics differentially in soils varying in texture. Soil Biol. Biochem. 45, 8-13. https://doi.org/10.1016/j. soilbio.2011.10.003

Melero S., López-Garrido R., Murillo J.M. y Moreno F. (2009). Conservation tillage: Short-and long-term effects on soil carbon fractions and enzymatic activities under Mediterranean conditions. Soil Till. Res. 104 (2), 292-298. https://doi.org/10.1016/j.still.2009.04.001

Minitab 18 Statistical Software (2018). Language packespañol, v.17.2.1. Minitab Inc., State College, Pennsylvania, EUA [en línea]. https://www.minitab.com/ es-mx/company/ 15/07/2018.

Nannipieri P., Ascher J., Ceccherini M., Landi L., Pietramellara G. y Renella G. (2003). Microbial diversity and soil functions. Eur. J. Soil Sci. 54 (4), 655-670. https:// doi.org/10.1046/j.1351-0754.2003.0556.x

Nelson D.W. y Sommers L.E. (1996). Total carbon, organic carbon, and organic matter. En: Methods of soil analysis: Part 3 - chemical methods (Sparks D.L., Ed.). 
Soil Science Society of America, Madison, WI, EUA, 961-1010. https://doi.org/10.2136/sssabookser5.3.c34 Pampillón-González L., Luna-Guido M., Ruiz-Valdiviezo V.M., Franco-Hernández O., Fernández-Luqueño F., Paredes-López O., Hernández G. y Dendooven L. (2017). Greenhouse gas emissions and growth of wheat cultivated in soil amended with digestate from biogas production. Pedosphere 27 (2), 318-327. https://doi. org/10.1016/S1002-0160(17)60319-9

Paustian K., Six J., Elliott E.T. y Hunt H.W. (2000). Management options for reducing $\mathrm{CO}_{2}$ emissions from agricultural soils. Biogeochemistry 48 (1), 147-163. https://doi.org/10.1023/A:100627133

Perelo L.W. y Munch J.C. (2005). Microbial immobilisation and turnover of ${ }^{13} \mathrm{C}$ labelled substrates in two arable soils under field and laboratory conditions. Soil Biol. Biochem. 37, 2263-2272. https://doi. org/10.1016/j.soilbio.2005.02.039

Pérez A., Céspedes C. y Núñez P. (2008). Caracterización física-química y biológica de enmiendas orgánicas aplicadas en la producción de cultivos en República Dominicana. Rev. Cienc. Suelo Nutr. 8 (3), 10-29. https://doi.org/10.4067/S0718-27912008000300002

Perucci P., Dumontet S., Bufo S.A., Mazzatura A. y Casucci C. (2000). Effects of organic amendment and herbicide treatment on soil microbial biomass. Biol. Fert. Soils 32 (1), 17-23. https://doi.org/10.1007/s003740000

Pires C.V., Schaefer C.E.R.G., Hashigushi A.K., Thomazini A. y Mendonça E.S. (2017). Soil organic carbon and nitrogen pools drive soil $\mathrm{C}-\mathrm{CO}_{2}$ emissions from selected soils in Maritime Antarctica. Sci. Total Environ. 596, 124-135. https://doi.org/10.1016/j.scitotenv.2017.03.144

Potisek-Talavera M.D.C., Figueroa-Viramontes U., González-Cervantes G., Jasso-Ibarra R. y OronaCastillo I. (2010). Aplicación de biosólidos al suelo y su efecto sobre contenido de materia orgánica y nutrimentos. Terra Latinoamericana 28 (4), 327-333.

Praspaliauskas M. y Pedisius N. (2017). A review of sludge characteristics in Lithuania's wastewater treatment plants and perspectives of its usage in thermal processes. Renew. Sust. Energ. Rev. 67, 899-907. https:// doi.org/10.1016/j.rser.2016.09.041

Rhoades J.D. (1982). Cation exchange capacity. En: Methods of soil analysis: Part 2 - chemical and microbiological properties (Page A.L., Ed.). Soil Science Society of America, Madison, WI, EUA, 149-157. https://doi.org/10.2134/agronmonogr9.2.2ed.c8

Rhoades J.D. (1996). Salinity: Electrical conductivity and total dissolved salts. En: Methods of soil analysis: Part 3 - chemical methods (Sparks D.L., Ed.). Soil Science Society of America, Madison, WI, EUA, 417-435. https://doi.org/10.2136/sssabookser5.3.c14
Rigby H., Clarke B.O., Pritchard D.L., Meehan B., Beshah F., Smith S.R. y Porter N.A. (2016). A critical review of nitrogen mineralization in biosolids-amended soil, the associated fertilizer value for crop production and potential for emissions to the environment. Sci. Total Environ. 541, 1310-1338. https://doi.org/10.1016/j. scitotenv.2015.08.089

Rojas-Oropeza M., Dendooven L., Garza-Avendaño L., Souza V., Philippot L. y Cabirol N. (2010). Effects of biosolids application on nitrogen dynamics and microbial structure in a saline-sodic soil of the former Lake Texcoco (Mexico). Bioresource Technol. 101 (7), 2491-2498. https://doi.org/10.1016/j. biortech.2009.10.088

Roohi M., Riaz M., Arif M.S., Shahzad S.M., Yasmeen T., Riaz M.A., Tahir S. y Mahmood K. (2016). Varied effects of untreated textile wastewater onto soil carbon mineralization and associated biochemical properties of a dryland agricultural soil. J. Environ. Manage. 183, 530-540. https://doi.org/10.1016/j.jenvman.2016.09.005

Rustad L.E.J.L., Campbell J., Marion G., Norby R., Mitchell M., Hartley A., Cornelissen J.H.C. y Gurevitch J. (2001). A meta-analysis of the response of soil respiration, net nitrogen mineralization, and aboveground plant growth to experimental ecosystem warming. Oecologia 126 (4), 543-562. https://doi.org/10.1007/ s004420000544

Sánchez-Monedero M.A., Mondini C., De Nobili M., Leita L. y Roig A. (2004). Land application of biosolids. Soil response to different stabilization degree of the treated organic matter. Waste Manage. 24 (4), 325-332. https:// doi.org/10.1016/j.wasman.2003.08.006

Sánchez-Monedero M.A., Mondini C., Cayuela M.L., Roig A., Contin M. y de Nobili M. (2008). Fluorescein diacetate hydrolysis, respiration and microbial biomass in freshly amended soils. Biol. Fert. Soils 44 (6), 885890. https://doi.org/10.1007/s00374-007-0263-1

Sciubba L., Cavani L., Negroni A., Zanaroli G., Fava F., Ciavatta C. y Marzadori C. (2014). Changes in the functional properties of a sandy loam soil amended with biosolids at different application rates. Geoderma 221, 40-49. https://doi.org/10.1016/j.geoderma.2014.01.018

SEMARNAT (2002). Norma Oficial Mexicana NOM021-SEMARNAT-2000. Especificaciones de fertilidad, salinidad y clasificación de suelos, estudio, muestreo y análisis. Secretaría del Medio Ambiente y Recursos Naturales. Diario Oficial de la Federación, 31 de diciembre.SEMARNAT (2003). Norma Oficial Mexicana NOM-004-SEMARNAT-2002. Protección ambiental. Lodos y biosólidos. Especificaciones y límites máximos permisibles de contaminantes para 
su aprovechamiento y disposición final. Secretaría del Medio Ambiente y Recursos Naturales. Diario Oficial de la Federación, 15 de agosto.Shirazi M.A. y Boersma L. (1984). A unifying quantitative analysis of soil texture 1. Soil Sci. Soc. Am. J. 48 (1), 142-147. https:// doi.org/10.2136/sssaj1984.03615995004800010026x

Singh K. (2016). Microbial and enzyme activities of saline and sodic soils. Land Degrad. Dev. 27 (3), 706-718. https://doi.org/10.1002/ldr.2385

Sofo A., Scopa A., Dumontet S., Mazzatura A. y Pasquale V. (2012). Toxic effects of four sulphonylureas herbicides on soil microbial biomass. J. Environ. Sci. Heal. B. 47 (7), 653-659. https://doi.org/10.1080/03601234 .2012 .669205

Srivastava P.K., Gupta M., Singh N. y Tewari S.K. (2016). Amelioration of sodic soil for wheat cultivation using bioaugmented organic soil amendment. Land Degrad. Dev. 27 (4), 1245-1254. https://doi.org/10.1002/ ldr.2292

Studdert G.A., Domingo M.N., García G V., Monterubbianesi M G. y Domínguez G.F. (2017). Carbono orgánico del suelo bajo sistemas de cultivo contrastantes y su relación con la capacidad de proveer nitrógeno. Ciencia del Suelo 35 (2), 285-299.

Sumner M.E. (1993). Sodic soils - New perspectives. Aust. J. Soil Res. 31 (6), 683-750. https://doi.org/10.1071/ SR9930683

Tejada M., García C., González J.L. y Hernández M.T. (2006). Use of organic amendment as a strategy for saline soil remediation: influence on the physical, chemical and biological properties of soil. Soil Biol. Biochem. 38 (6), 1413-1421. https://doi.org/10.1016/j. soilbio.2005.10.017

Thangarajan R., Bolan N.S., Tian G., Naidu R. y Kunhikrishnan A. (2013). Role of organic amendment application on greenhouse gas emission from soil. Sci. Total Environ. 465, 72-96. https://doi.org/10.1016/j. scitotenv.2013.01.031

Thomas G.W. (1982). Exchangeable cations. En: Methods of soil analysis: Part 2 - chemical and microbiological properties (Page A.L., Ed.). Soil Science Society of America, Madison, WI, EUA, 159-165. https://doi. org/10.2134/agronmonogr9.2.2ed.c9

Thomas G.W. (1996). Soil pH and soil acidity. En: Methods of soil analysis: Part 3 - chemical methods (Sparks D.L., Ed.). Soil Science Society of America, Madison, WI, EUA, 475-490. https://doi.org/10.2136/ sssabookser5.3.c16
Tian G., Granato T.C., Cox A.E., Pietz R.I., Carlson C.R. y Abedin Z. (2009). Soil carbon sequestration resulting from long term application of biosolids for land reclamation. J. Environ. Qual. 38, 61-74. https://doi. org/10.2134/jeq2007.0471

Torri S.I., Correa R.S. y Renella G. (2017). Biosolid application to agricultural land -A contribution to global phosphorus recycle: A review. Pedosphere 27 (1), 1-16. DOI:10.1016/S1002-0160(15)60106-0

Trivedi P., Singh K., Pankaj U., Verma S.K., Verma R.K. y Patra D.D. (2017). Effect of organic amendments and microbial application on sodic soil properties and growth of an aromatic crop. Ecol. Eng. 102, 127-136. https://doi.org/10.1016/j.ecoleng.2017.01.046

Wang C., Zhou Z., Liu H., Li J., Wang Y. y Xu H. (2017). Application of acclimated sewage sludge as a bioaugmentation/bio-stimulation strategy for remediating chlorpyrifos contamination in soil with/without cadmium. Sci. Total Environ. 579, 657-666. https:// doi.org/10.1016/j.scitotenv.2016.11.044

Wang H., Kimberley M.O. y Schlegelmilch M. (2003). Biosolids-derived nitrogen mineralization and transformation in forest soils. J. Environ. Qual. 32 (5), 1851-1856. https://doi.org/10.2134/jeq2003.1851

Wang H., Boutton T.W., Xu W., Hu G., Jiang P. y Bai E. (2015). Quality of fresh organic matter affects priming of soil organic matter and substrate utilization patterns of microbes. Sci. Rep.-U.K. 5, 10102. https://doi. org/10.1038/srep10102

Wong V.N., Dalal R.C. y Greene R.S. (2009). Carbon dynamics of sodic and saline soils following gypsum and organic material additions: a laboratory incubation. Appl. Soil Ecol. 41 (1), 29-40. https://doi. org/10.1016/j.apsoil.2008.08.006

Wong V.N., Greene R.S.B., Dalal R.C. y Murphy B.W. (2010). Soil carbon dynamics in saline and sodic soils: a review. Soil Use Manage. 26 (1), 2-11. https://doi. org/10.1111/j.1475-2743.2009.00251.x

Zanor G.A., López-Pére M.E., Martínez-Yáñez R., Ramírez-Santoyo L.F., Gutiérrez-Vargas S., y LeónGalván M.F. (2018). Mejoramiento de las propiedades físicas y químicas de un suelo agrícola mezclado con lombricompostas de dos efluentes de biodigestor. Ingeniería Investlgación y Tecnología, 19 (4), 1-10. https:// dx.doi.org/10.22201/fi.25940732e.2018.19n4.036

Zhang Q., Hu J., Lee D.J., Chang Y. y Lee Y.J. (2017). Sludge treatment: Current research trends. Bioresource Technol. 243, 1159-1172. https://doi.org/10.1016/j. biortech.2017.07.070 